\title{
Dysregulated metabolic enzymes and metabolic reprogramming in cancer cells (Review)
}

\author{
ANNAPOORNA SREEDHAR and YUNFENG ZHAO
}

Department of Pharmacology, Toxicology and Neuroscience, LSU Health Sciences Center

Shreveport, LA 71130-3932, USA

Received June 29, 2017; Accepted August 17, 2017

DOI: $10.3892 /$ br.2017.1022

\begin{abstract}
Tumor cells carry various genetic and metabolic alterations, which directly contribute to their growth and malignancy. Links between metabolism and cancer are multifaceted. Metabolic reprogramming, such as enhanced aerobic glycolysis, mutations in the tricarboxylic acid (TCA) cycle metabolic enzymes, and dependence on lipid and glutamine metabolism are key characteristics of cancer cells. Understanding these metabolic alterations is crucial for development of novel anti-cancer therapeutic strategies. In the present review, the broad importance of metabolism in tumor biology is discussed, and the current knowledge on dysregulated metabolic enzymes involved in the vital regulatory steps of glycolysis, the TCA cycle, the pentose phosphate pathway, and lipid, amino acid, and mitochondrial metabolism pathways are reviewed.
\end{abstract}

\section{Contents}

1. Introduction

2. Glycolysis

3. Tricarboxylic acid cycle

4. Pentose phosphate pathway

5. Amino acid metabolism

6. Lipid metabolism

7. Metabolic crosstalk

8. Central role of mitochondria

9. Conclusion

\section{Introduction}

Metabolic alteration is a hallmark of cancer cells (1). A growing body of evidence indicates that malignant transformation is

Correspondence to: Dr Yunfeng Zhao, Department of Pharmacology, Toxicology and Neuroscience, LSU Health Sciences Center, 1501 Kings Highway, Shreveport, LA 71130-3932, USA

E-mail: yzhao1@lsuhsc.edu

Key words: cancer metabolism, glycolysis, metabolic reprogramming, metabolic enzymes, lipid metabolism characterized by the occurrence of multiple changes in metabolic pathways that are linked to the synthesis of macromolecules (2). Metabolism is the fundamental architecture of cellular life. Typically, every cell in the body, either directly or indirectly, undergoes metabolism. Metabolism is a sum or a collection of biochemical reactions that produce energy for vital processes and for synthesizing macromolecules. Unsurprisingly, mitochondria, the power house of cells, perform a central role in energy metabolism. Either because of a direct impact or its pivotal role in signal transduction, mitochondria are hubs for metabolic alterations and reprogramming. Furthermore, mitochondria are involved in the production of adenosine triphosphate (ATP), and exert key roles in redox regulation, calcium homeostasis, cell signaling, cell death, and production of various intermediates that are necessary for macromolecule synthesis (3-6).

Increasing attention has been given to the role of mitochondrial metabolism in cancer biology. The complex connection between metabolism and tumorigenesis is a promising area of cancer research. Mounting evidence has demonstrated that targeting mitochondrial metabolism in cancer cells may present as a novel strategy for anti-cancer therapy (7-11). As summarized from current knowledge, the process of tumorigenesis and mitochondrial biology intercross at multiple levels as follows: i) Direct signals from mitochondria promote tumorigenesis; ii) oncogenic signaling pathways alter mitochondrial functions; iii) perturbation of mitochondrial functions have been shown to have a major role in regulating metabolism and bioenergetics; iv) mutations in mitochondrial DNA, proteins and enzymes result in altered levels of metabolites, which support tumor development and progression. The current review focuses on the importance of various such classic alterations in cancer metabolism. Hence, by understanding this aspect of metabolism, cancer biology may be better understood and novel anti-cancer drugs may be developed.

\section{Glycolysis}

All parts of the body require energy to work and this energy is derived from consumption of food. Typically, all food is broken down into smaller parts to generate the energy source, ATP. ATP is a chemical energy generated via controlled oxidation of glucose and other molecules. The process of the breakdown 


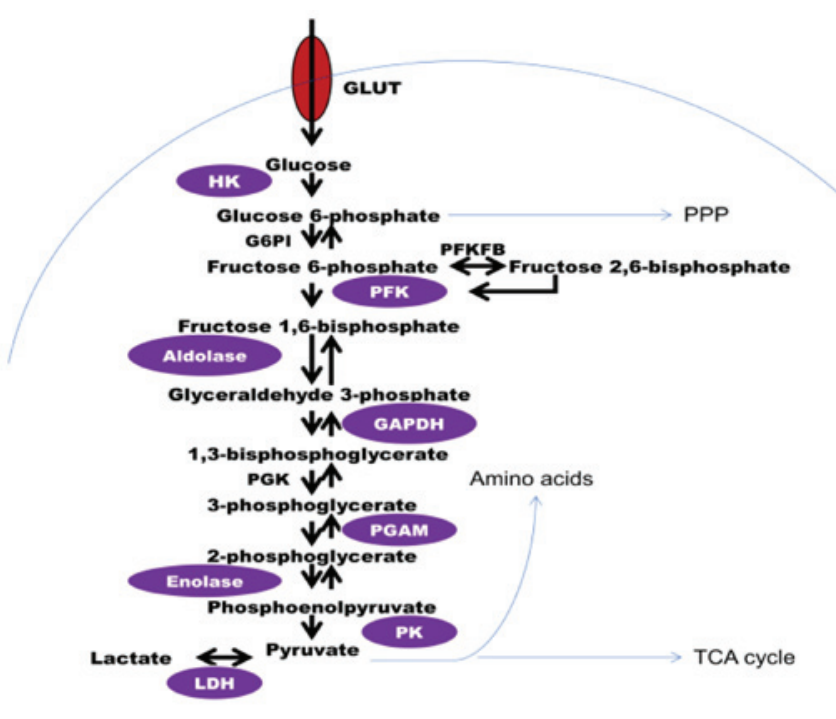

Figure 1. Glucose metabolism. Glycolysis is the catabolic process in which glucose is broken down to pyruvate via these 10 enzymatic steps. Numerous glycolytic enzymes are altered in cancer cells (purple ovals). GLUT, glucose transporter; HK, hexokinase; PPP, pentose phosphate pathway; PFKFB, 6-phosphofructo-2-kinase/fructose 2,6-bisphosphatase; GAPDH, glyceraldehyde-3-phosphate dehydrogenase; PGAM, phosphoglycerate mutase; PK, pyruvate kinase; LDH, lactate dehydrogenase; TCA, tricarboxylic acid cycle.

of glucose, termed glycolysis, occurs in the cytoplasm of mammalian cells. Glucose from food is taken up by specific glucose transporters in the cell surface, and via a series of enzyme-catalyzed reactions, broken down to pyruvate, the end-product of glycolysis under aerobic conditions (Fig. 1). If there is a lack of oxygen supply, pyruvate is converted to lactate (anaerobic glycolysis). Theoretically, one molecule of glucose yields two molecules of pyruvate and two molecules of ATP via glycolysis.

Since the early twentieth century, abnormalities of glycolysis in cancer cells have been observed. Warburg (12), a German physiologist and a Nobel laurate, observed that tumor cells depend solely on glycolysis for energy production, even with an ample quantity of oxygen. This phenomenon is since termed the Warburg effect of cancer cells. This raises the question as to why cancer cells switch their metabolism to aerobic glycolysis, unlike normal cells, which depend on oxidative phosphorylation for energy production. While the exact reasons remain unclear, the current explanations include: i) Aerobic glycolysis, although less efficient than the classic oxidative phosphorylation, provides rapid supply of ATP; ii) glycolysis intermediates provide sufficient building blocks for macromolecule synthesis required for the enhanced cell proliferation. Due to this feature of cancer cells, studies have been focused on novel strategies to selectively inhibit glucose metabolism and/or glucose transport in cancer cells (13-16).

Marked progress has been made in understanding the molecular mechanisms leading to constitutive upregulation of glycolysis in tumor cells. Various glycolytic enzymes are multifunctional proteins whose expression levels are often increased in cancer cells. For example, hexokinase (HK), the enzyme that converts glucose to glucose 6-phosphate (G6P), the first step of glycolysis, is involved in transcription regulation, and its expression is often upregulated in tumor cells $(17,18)$. The majority of malignant cells display enhanced expression levels of type II isoform (HK-II), which may contribute to the elevated glycolysis (19,20). Phosphofructokinase (PFK), the enzyme that catalyzes the rate limiting step of glycolysis, has been identified to be upregulated in types of breast cancer $(21,22)$. Another critical regulator of glycolysis is the enzyme 6-phosphofructo2-kinase/fructose 2,6-bisphosphatase (Pfkfb), a family of bifunctional enzymes that control the levels of fructose 2,6-bisphosphate, which in turn is a powerful allosteric activator of PFK1. Two Pfkfb isoforms, type 2 and 3, are associated with cancers (23-26). Subsequently, the enzyme aldolase that catalyzes the reversible conversion of fructose1,6-bisphosphate to glyceraldehyde-3-phosphate and dihydroxyacetone phosphate, has been demonstrated to be overexpressed in squamous cell lung carcinoma (27). The wellknown classic glycolytic enzyme, glyceraldehyde-3-phosphate dehydrogenase (GAPDH; the housekeeping gene) is also implicated in cancer. Overexpression of GAPDH is considered an important feature of numerous types of cancer (28-30). GAPDH has been proposed as a promising target for the treatment of carcinomas (31). Pyruvate kinase (PK), the enzyme that catalyzes the irreversible phosphoryl group transfer from phosphoenolpyruvate to pyruvate, yielding pyruvate and ATP, appears to be involved in cancer; previous studies and our findings have demonstrated that tumor cells overexpress the type M2 isoform, PKM2 (32-35). As the majority of cancer cells are dependent on aerobic glycolysis for ATP production, the enzyme, lactate dehydrogenase (LDH), which catalyzes the conversion of pyruvate to lactate, is the key to determining the glycolytic phenotype of cancer cells. Thus, LDH is a promising target for anti-cancer therapy. The inhibition of LDH suppresses tumor progression of lymphomas and pancreatic cancer xenografts (36). These results indicate that selectively targeting glycolysis and/or glycolytic enzymes in tumor cells may present as an effective approach for the treatment of different types of cancer.

\section{Tricarboxylic acid (TCA) cycle}

The Krebs cycle (the citric acid cycle or the TCA) is a series of chemical reactions that generate energy via the oxidation of pyruvate (Fig. 2). TCA cycles occur in all aerobic living organisms. It provides precursors for biosynthesis of compounds (such as amino acids), and nicotinamide adenine dinucleotide (NADH), which is later used by the electron transport chain to generate energy by converting NADH to NAD+. The TCA cycle is the central metabolic hub of the cell that occurs primarily in the mitochondria in contrast to glycolysis, which occurs in the cytosol. Even a minor alteration in these processes markedly influences mitochondrial energy production. Although mutations in mitochondrial DNA have been evaluated for over two decades (37-39), much attention has been focused on the identification of mutations in various TCA cycle enzymes $(40,41)$. The cycle consists of eight steps catalyzed by eight different enzymes. Mutations in genes that encode enzymes aconitase, isocitrate dehydrogenase (IDH), succinate dehydrogenase (SDH), and fumarate hydratase (FH) may lead to cancer. Aconitase catalyzes isomerization of citrate to isocitrate via cis-aconitase. Altered expression levels of aconitase are implicated in human prostate cancer, wherein the normal citrate- 


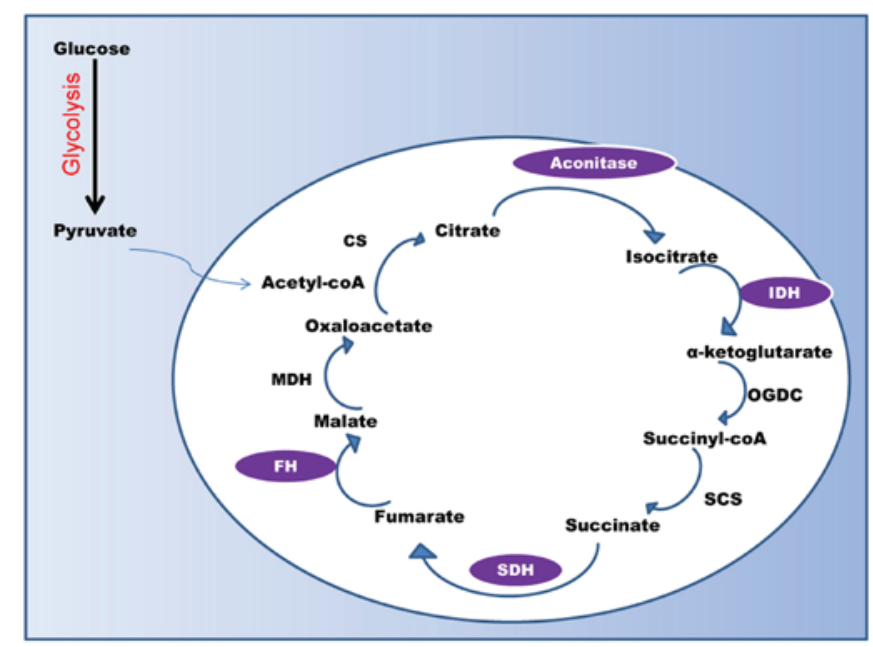

Figure 2. Krebs cycle. The TCA is comprised of series of enzyme-catalyzed reactions, located in the mitochondrial matrix. Various enzymes (purple ovals) of the TCA cycle are mutated and/or altered in many types of cancer. TCA, tricarboxylic acid cycle; IDH, isocitrate dehydrogenase; OGDC, oxoglutarate dehydrogenase complex; SCS, succinyl-CoA synthetase; SDH, succinate dehydrogenase; $\mathrm{FH}$, fumarate hydratase; $\mathrm{MDH}$, malate dehydrogenase; CS, citrate synthase.

producing glandularsecretory epithelialcells undergo a metabolic transformation to malignant citrate-oxidizing cells, leading to abnormal citrate metabolism and prostate malignancy (42). IDH converts isocitrate to $\alpha$-ketoglutarate $(\alpha-K G)$. Glioblastoma multiforme, one of the most common and lethal types of brain cancer, is characterized by IDH1 gene mutations (43). Similar studies discovered mutations in IDH1 and IDH2 genes in the pathogenesis of malignant gliomas (44). Mutations that occur in single amino acid residue of IDH1 active sites not only result in the novel ability for the mutant enzyme to convert $\alpha$-KG to 2-hydroxyglutarate, which is proposed to contribute to the formation and malignant progression of gliomas (45). FH is the enzyme that converts fumarate to malate, and mutations in the FH gene are associated with cutaneous, uterine and aggressive forms of renal cancer (46-48). Cancer cells that harbor FH mutations produce up to 100-fold more fumarate, and seven-fold more succinate, but decreased levels of citrate and malate (49). FH deficiency in tumor cells alters redox homeostasis to promote tumorigenesis (48). Mutations in the enzyme SDH, which catalyzes the oxidation of succinate to fumarate, are implicated in pheochromocytoma, paraganglioma, renal cell carcinoma and papillary thyroid cancers (50-52). Reduced expression and loss of heterozygosity of the SDH gene are observed in gastric and colon carcinoma (53). SDH downregulation results in succinate accumulation leading to transmission of an oncogenic signal from mitochondria to the cytosol (54).

\section{Pentose phosphate pathway (PPP)}

The PPP, which branches out from glycolysis at the first committed step is the major catabolic pathway of glucose for nucleotide synthesis in cancer cells (55-57). The conversion of glucose to G6P, which is catalyzed by the enzyme HK, is a common precursor for various metabolic glucose-consuming routes (Fig. 3). Through this pathway, cancer cells produce large quantities of ribose-5 phosphate (a precursor for nucleotide

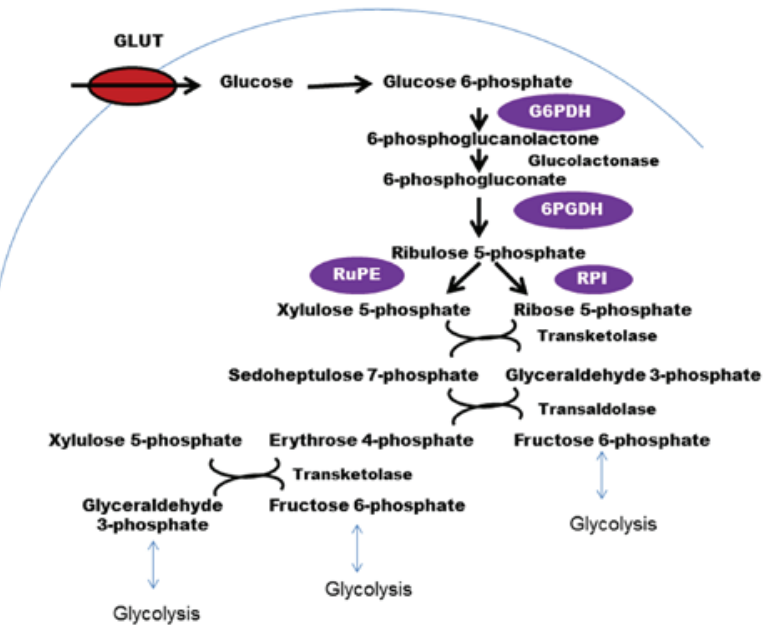

Figure 3. PPP, which branches out from glycolysis at the first committed stage of glucose metabolism, is required for nucleotide synthesis in cancer cells. Numerous enzymes of the PPP are associated with various types of cancer. PPP, pentose phosphate pathway; GLUT, glucose transporter; G6PDH, glucose 6-phosphate dehydrogenase; 6PGDH, 6-phosphogluconate dehydrogenase; RuPE, ribulose-5-phosphate-3-epimerase; RPI, ribose-5-phosphate isomerase.

synthesis) and NAPDH (a cofactor used in anabolic reactions). PPP runs parallel to glycolysis and activation of these signaling pathways is a common hallmark of tumor cells $(58,59)$. As cancer cells are rapidly dividing, the cells require a constant supply of nucleotides, and the majority of the pentose phosphates are derived from the PPP. Thus, PPP may influence the glycolytic flux. Various enzymes that execute the PPP are implicated in different types of cancer. G6P dehydrogenase (G6PD or G6PDH), the enzyme that catalyzes the rate-limiting step in the PPP, and generates the first NADPH, is highly overexpressed in certain tumors (60). Elevated levels of G6PD in association with higher levels of PPP-derived metabolites are responsible for clear-cell renal carcinoma-associated metabolic alterations (61). Overexpression of G6PD in human U2OS bone osteosarcoma epithelial cells enhances the PPP-dependent production of NADPH (62). The same group also demonstrates that simultaneous inhibition of glycolysis and PPP using 2-deoxy-d-glucose and 6-aminonicotinamide, respectively, induces oxidative stress and sensitizes malignant human cancer cell lines to radiotherapy, presumably via the induction of multiple cell death modalities, including apoptosis, necrosis and mitotic catastrophe (63). The next enzyme that has a role in cancer is 6-phosphogluconate dehydrogenase (6PGDH). 6PGDH catalyzes the oxidative decarboxylation of 6-phosphogluconate to ribulose 5-phosphate with a reduction of NADP to NADPH. 6PGDH has been shown to be critical for lung carcinogenesis and its inhibition may be a novel strategy to treat glycolytic lung tumors (55). Ribulose-5 phosphate isomerase, another critical enzyme in the PPP, which catalyzes the conversion of ribulose- 5 phosphate to ribose- 5 phosphate and xylulose- 5 phosphate (Xu5P), is also associated with cancer (55). Ribose-5 phosphate is important as it is a precursor for de novo nucleotide synthesis in rapidly proliferating cancer cells. Xu5P increases the levels of PFKFB, which activates PFK1 and increases glycolytic flux (64). Thus, all of these studies implicate that the regulation of PPP is vital for cancer cell survival and proliferation. Furthermore, increased 


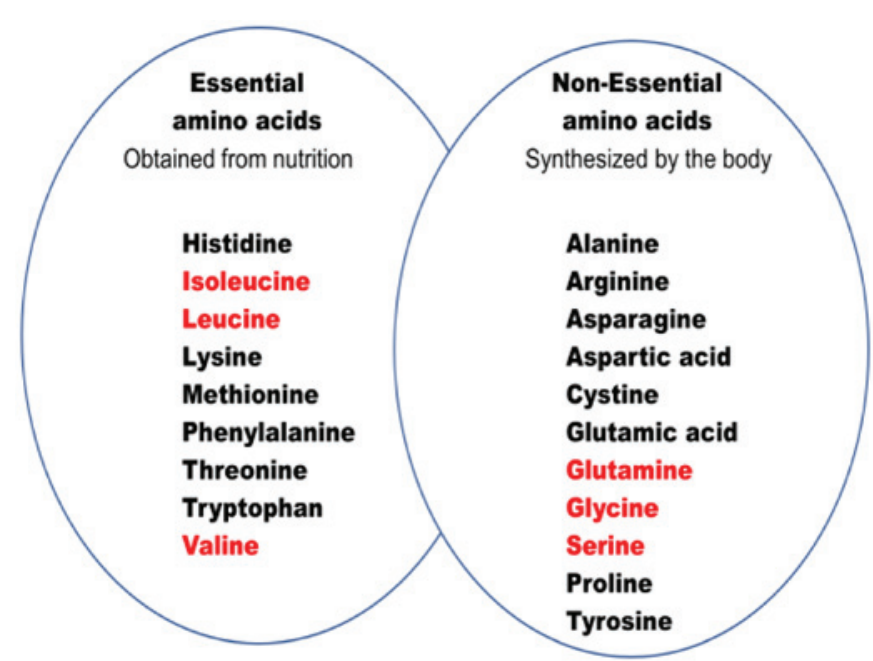

Figure 4. Essential and non-essential amino acids.

glycolytic flux in cancer cells may be regulated directly or indirectly by PPP, and hence, this may represent a promising strategy for treatment of cancer cells.

\section{Amino acid metabolism}

Amino acids are one of the major fuels for biosynthetic reactions (Fig. 4), and therefore, are intricately involved in cellular metabolism. From the above-mentioned studies, it is evident that cancer cells are characterized by altered metabolism and/or dysregulated metabolic pathways. Amino acids are of utmost necessity for cancer cell proliferation, as they are the major source of nutrients. Even a slight alteration in the biosynthetic pathways may have an impact on amino acid synthesis. Despite glutamine being a nonessential amino acid, it is one of the major fuels for cancer cells (65-67). In cancer cells, glutamine is a primary mitochondrial substrate required to maintain mitochondrial membrane potential, integrity and for NADPH production (65). Certain tumor cells are characterized by 'glutamine addiction', the ability of cancer cells to exhibit a high rate of glutamine uptake. Glutamine catabolism or glutaminolysis is elevated in certain types of tumor (68-70). Enzyme glutaminase converts glutamine to glutamate and ammonia. Glutamate is further converted to $\alpha-\mathrm{KG}$ and enters the TCA cycle. Emerging evidence indicates the role of glutamate and glutamate receptors in human rhabdomyosarcoma/medulloblastoma (TE671), neuroblastoma (SK-NA-S), thyroid carcinoma (FTC 238), lung carcinoma (SK-LU-1), astrocytoma (MOGGCCM), multiple myeloma (RPMI-8226), glioma (U87-MG and U343), lung carcinoma (A549), colon adenocarcinoma (HT 29), T cell leukemia cells (Jurkat E6.1), breast carcinoma (T47D) and colon adenocarcinoma (71). Glutamine is also involved in activating mechanistic target of rapamycin complex $1(68,72)$. Glycine, another nonessential and one of the simplest amino acids, has also been implicated in cancer $(73,74)$. Glycine is a significant constituent of proteins in the body, which build tissues and organs. It is the most abundant type of amino acid in the body and one of the most important regulators of inflammation (75-77). Glycine metabolism has also been demonstrated to be upregulated in non-small cell lung cancers $(74,78)$. Studies have demonstrated

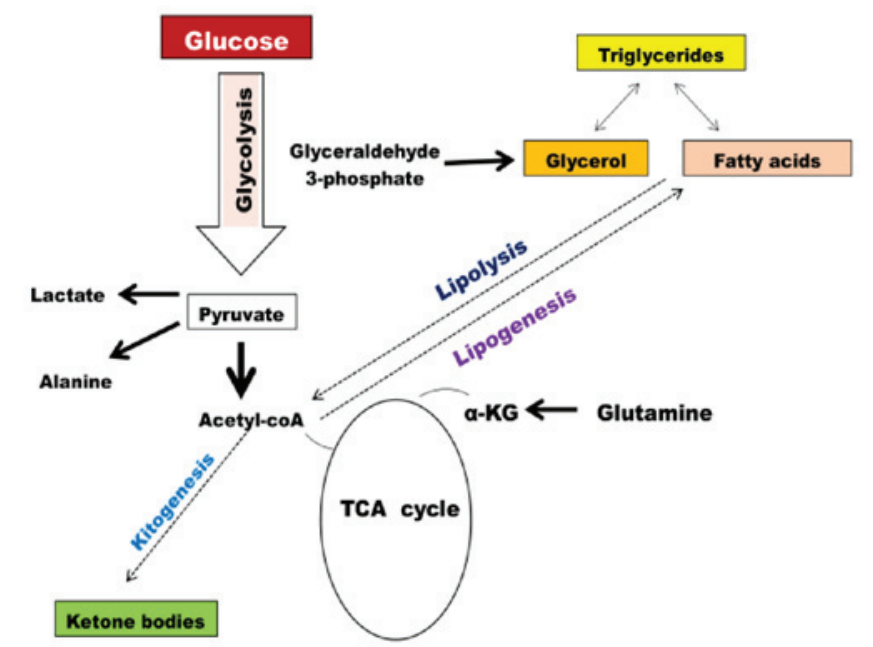

Figure 5. Lipid metabolism. The interactions between glycolysis, Krebs cycle and lipid metabolism. Lipogenesis is the formation of lipids, whereas lipolysis is the breakdown of lipids. Triglycerides are made up of glycerol and fatty acids. Fatty acids undergo B-oxidation producing acetyl CoA, which enters the TCA cycle. TCA, tricarboxylic acid cycle; $\alpha$-KG, $\alpha$-ketoglutarate.

that glycine stimulates proliferation of tumor cells, and cancer cells deprived of glycine indicated a significant reduction in cell growth $(74,79)$. Serine, another important nonessential amino acid that participates in nucleotide synthesis, has been shown to be upregulated in breast cancer $(74,80)$. Studies using melanoma cells have demonstrated that significant portions of serine are converted to glycine (81). Serine, glycine, and folate (vitamin B9) are constitutively active in various tumor cells $(74,79,82)$.

\section{Lipid metabolism}

The role of lipid metabolism in cancer cells has long been disregarded; over the past decade, the increased rate of lipid metabolism in cancer cells is being recognized as the prominent hallmark of transformed cells (83-85). Lipids are a diverse group of molecules composed of fat, triglycerides, phospholipid, cholesterols and cholesterol esters (Fig. 5). Lipids form the major component of cell membranes (phospholipid bilayer), hormones (steroid hormones, such as cholesterol) and certain lipid-soluble vitamins. Hence, lipids perform various roles in the body, from providing energy to muscles to producing hormones (86). In rapidly proliferating cancer cells, there is an overwhelming requirement for macromolecule synthesis. Hence, cancer cells also demonstrate a high dependence on lipids (83). One of the enzymes involved in the synthesis of de novo fatty acids is ATP citrate lyase (ACLY). ACLY catalyzes the conversion of mitochondrial-derived citrate to oxaloacetate and cytosolic acetyl-CoA. Thus, ACLY links de novo lipogenesis to gluconeogenesis and the Krebs cycle (87). Studies have demonstrated that higher expression levels of ACLY correlated with advanced stages of cancer and lymph node metastasis in tissue samples from gastric adenocarcinoma patients (88). However, targeting ACLY by microRNA-22 (miR-22) suppresses cancer cell proliferation and invasion in osteosarcoma, prostate, cervical and lung cancer cells (89). Another study demonstrates that ACLY is 
required for low molecular weight isoform of cyclin E mediated transformation, migration, and invasion of breast cancer cells in vitro along with tumor growth in vivo (90). Acetyl-CoA carboxylase (ACC) is the rate-limiting enzyme in fatty acid synthesis. ACC carboxylates acetyl-CoA to form malonyl-CoA. In patients with squamous cell carcinoma of the head and neck, there is an association between phosphorylated AMP-activated protein kinase and ACC expression, and the therapeutic outcome is that high phosphorylated-ACC expression is associated with a worse overall survival rate in the patients (91). Similarly, ACC1 expression is upregulated in patients with hepatocellular carcinoma (HCC), and upregulation of ACC1 is also significantly correlated with the poorer overall survival of, and disease recurrence in HCC patients (92). Fatty acid synthase (FASN), which catalyzes the final step in fatty acid synthesis, is often overexpressed in human cancers $(93,94)$. Inhibition of FASN suppresses invasion and migration of HCC cells (95). In contrast to enhanced fatty acid synthesis, certain types of cancer rely on the mitochondrial fatty acid oxidation (FAO) for ATP production (96). Although the mechanism that upregulates FAO in cancer remains unclear, it is proposed that FAO may confer benefits beyond ATP production (96). The FAO contributes to maintenance of redox homeostasis, and cell survival in hematopoietic stem cells and leukemia cells (97). Carnitine palmitoyltransferase (CPT1), the enzyme that catalyzes the initial step of FAO, is implicated in various types of cancer $(96,98,99)$. CPT1 upregulation increases FAO, ATP production and endows resistance to metabolic stress.

\section{Metabolic crosstalk}

Increased glycose consumption, lactate production, PPP, lipid metabolism, and amino acid synthesis are commonly observed metabolic profile in almost all types of cancer cell. This type of metabolic profiling of tumor cells has been proposed to support their rapid cell growth (100). High rates of glycolysis leading to lactate production (aerobic glycolysis or the Warburg effect) distinguish cancer cells from normal cells $(12,13)$. Glucose is a remarkable fuel for cancer cell, and a precursor for the supply of various metabolic intermediates, which are utilized for lipid, amino acid and nucleotide synthesis. Glutamine serves as another important source of fuel in cancer cells (65). Glutamine enters the mitochondria to replenish the Krebs cycle intermediates (66-69). Glutamine enters the Krebs cycle to produce $\alpha-K G$, succinate, fumarate and malate. Highly proliferative cancer cells have a high demand for the rapid synthesis of lipids, amino acids and nucleotides (83-87). Tumor cells also divert carbon from glycolysis into the PPP (58), by which cancer cells synthesize macromolecules, such as nucleic acids. In addition, citrate and acetyl-coA are key intermediates for lipid synthesis (88-90). Since these metabolic pathways are interconnected, understanding the mechanism(s) leading to this metabolic switch in cancer cells is of utmost importance.

\section{Central role of mitochondria}

Mitochondrial metabolism has emerged as a key target for cancer therapy $(8,9)$. Mitochondria are important bioenergetics and biosynthetic organelles, responsible for producing ATP and various intermediates required for macromolecule synthesis. In addition to participating in energy metabolism, mitochondria participate in calcium homeostasis, production of reactive oxygen species (ROS), regulation of apoptosis and cell signaling pathways (3-6). Cancer cells have been shown to exhibit various degrees of mitochondrial abnormalities, which render mitochondria a suitable target for anti-cancer drugs (7-9). Mutations in mitochondrial DNA- and nuclear DNA-encoded mitochondrial genes have been observed in various types of human cancer (101-103). These mutations range from single nucleotide polymorphisms to severe insertions/deletions and even chain termination. Furthermore, as mitochondria are the primary source of ROS generation, mitochondrial DNA is continuously exposed to oxidative stress and damage. A previous study investigated the contributions of mitochondrial mutations to tumor cell proliferation and metastasis (104). With increasing mutations, mitochondrial respiratory capacity has been shown to decrease progressively $(104,105)$. In addition, defects in the mitochondrial respiratory chain may either promote or inhibit apoptosis (106). Programmed cell death or apoptosis is a complex signaling cascade, which is tightly regulated by proteases, termed caspases. Initiation of apoptosis and ROS production are closely associated with mitochondria (107). Osellame et al (107), demonstrated that loss of mitochondrial outer membrane permeability is characteristic of intrinsic apoptosis. In addition, ROS may mediate pro- and anti-apoptotic effects (108). During the last decade, the implication of polyamines in initiation of apoptosis has been the focus of investigations $(109,110)$. Novel interactions between polyamine and mitochondria have recently been summarized in a review by Grancara et al (111). There is increasing interest in understanding multiple facets of mitochondrial biology that contribute to cancer. Mitochondria act as a central hub for cell survival, cell metabolism and cell death pathways. Taking into consideration the multifaceted role of mitochondria in tumorigenesis, targeting mitochondria may present an effective approach to treating cancer.

\section{Conclusion}

Metabolic reprogramming of cancer cells is recognized as one of the hallmarks of cancer. In this review article, the core dysregulated metabolic pathways and enzymes contributing to cancer cell proliferation, differentiation and metastasis, as well as the central role of mitochondria in orchestrating metabolic reprogramming were summarized. The close connection between these metabolic pathways, the role of mitochondria and redox regulation of tumor cells represents a promising strategy to target cancer growth. Thus, targeting these important metabolic enzymes and/or mitochondrial metabolic pathways may offer a valid and novel anti-cancer therapeutic strategy.

\section{References}

1. Hanahan D and Weinberg RA: Hallmarks of cancer: The next generation. Cell 144: 646-674, 2011.

2. Dang CV: Links between metabolism and cancer. Genes Dev 26: 877-890, 2012.

3. Newmeyer DD and Ferguson-Miller S: Mitochondria: Releasing power for life and unleashing the machineries of death. Cell 112: 481-490, 2003.

4. Wang X: The expanding role of mitochondria in apoptosis. Genes Dev 15: 2922-2933, 2001. 
5. Detmer SA and Chan DC: Functions and dysfunctions of mitochondrial dynamics. Nat Rev Mol Cell Biol 8: 870-879, 2007.

6. McBride HM, Neuspiel M and Wasiak S: Mitochondria: More than just a powerhouse. Curr Biol 16: R551-R560, 2006.

7. Wallace DC: Mitochondria and cancer. Nat Rev Cancer 12: 685-698, 2012

8. Weinberg SE and Chandel NS: Targeting mitochondria metabolism for cancer therapy. Nat Chem Biol 11: 9-15, 2015.

9. Wen S, Zhu D and Huang P: Targeting cancer cell mitochondria as a therapeutic approach. Future Med Chem 5: 53-67, 2013.

10. Wang F, Ogasawara MA and Huang P: Small mitochondriatargeting molecules as anti-cancer agents. Mol Aspects Med 31: 75-92, 2010.

11. Carew JS and Huang P: Mitochondrial defects in cancer. Mol Cancer 1: 9, 2002.

12. Warburg O: On the origin of cancer cells. Science 123: 309-314, 1956.

13. Vander Heiden MG, Cantley LC and Thompson CB Understanding the Warburg effect: The metabolic requirements of cell proliferation. Science 324: 1029-1033, 2009.

14. DeBerardinis RJ: Is cancer a disease of abnormal cellular metabolism? New angles on an old idea. Genet Med 10: 767-777, 2008.

15. Seyfried TN and Shelton LM: Cancer as a metabolic disease. Nutr Metab (Lond) 7: 7, 2010.

16. Pelicano H, Martin DS, Xu RH and Huang P: Glycolysis inhibition for anticancer treatment. Oncogene 25: 4633-4646, 2006.

17. Niederacher D and Entian KD: Characterization of Hex2 protein, a negative regulatory element necessary for glucose repression in yeast. FEBS J 200: 311-319, 1991.

18. Herrero P, Galíndez J, Ruiz N, Martínez-Campa C and Moreno F: Transcriptional regulation of the Saccharomyces cerevisiae HXK1, HXK2 and GLK1 genes. Yeast 11: 137-144, 1995.

19. Rempel A, Mathupala SP, Griffin CA, Hawkins AL and Pedersen PL: Glucose catabolism in cancer cells: Amplification of the gene encoding type II hexokinase. Cancer Res 56 : 2468-2471, 1996.

20. Bustamante E and Pedersen PL: High aerobic glycolysis of rat hepatoma cells in culture: Role of mitochondrial hexokinase. Proc Natl Acad Sci USA 74: 3735-3739, 1977.

21. El-Bacha T, de Freitas MS and Sola-Penna M: Cellular distribution of phosphofructokinase activity and implications to metabolic regulation in human breast cancer. Mol Genet Metab 79: 294-299, 2003

22. Zancan P, Sola-Penna M, Furtado CM and Da Silva D: Differential expression of phosphofructokinase-1 isoforms correlates with the glycolytic efficiency of breast cancer cells Mol Genet Metab 100: 372-378, 2010.

23. Clem BF, O'Neal J, Tapolsky G, Clem AL, Imbert-Fernandez Y, Kerr DA II, Klarer AC, Redman R, Miller DM, Trent JO, et al: Targeting 6-phosphofructo-2-kinase (PFKFB3) as a therapeutic strategy against cancer. Mol Cancer Ther 12: 1461-1470, 2013

24. Atsumi T, Chesney J, Metz C, Leng L, Donnelly S, Makita Z, Mitchell R and Bucala R: High expression of inducible 6-phosphofructo-2-kinase/fructose-2,6-bisphosphatase (iPFK-2; PFKFB3) in human cancers. Cancer Res 62: 5881-5887, 2002.

25. Moon JS, Jin WJ, Kwak JH, Kim HJ, Yun MJ, Kim JW, Park SW and Kim KS: Androgen stimulates glycolysis for de novo lipid synthesis by increasing the activities of hexokinase 2 and 6-phosphofructo-2-kinase/fructose-2,6-bisphosphatase 2 in prostate cancer cells. Biochem J 433: 225-233, 2011.

26. Okar DA, Manzano A, Navarro-Sabatè A, Riera L, Bartrons R and Lange AJ: PFK-2/FBPase-2: Maker and breaker of the essential biofactor fructose-2,6-bisphosphate. Trends Biochem Sci 26: 30-35, 2001

27. Li C, Xiao Z, Chen Z, Zhang X, Li J, Wu X, Li X, Yi H, Li M, Zhu $\mathrm{G}$, et al: Proteome analysis of human lung squamous carcinoma. Proteomics 6: 547-558, 2006.

28. Tokunaga K, Nakamura Y, Sakata K, Fujimori K, Ohkubo M, Sawada K and Sakiyama S: Enhanced expression of a glyceraldehyde-3-phosphate dehydrogenase gene in human lung cancers. Cancer Res 47: 5616-5619, 1987.

29. Schek N, Hall BL and Finn OJ: Increased glyceraldehyde3 -phosphate dehydrogenase gene expression in human pancreatic adenocarcinoma. Cancer Res 48: 6354-6359, 1988.

30. Epner DE, Partin AW, Schalken JA, Isaacs JT and Coffey DS: Association of glyceraldehyde-3-phosphate dehydrogenase expression with cell motility and metastatic potential of rat prostatic adenocarcinoma. Cancer Res 53: 1995-1997, 1993.
31. Krasnov GS, Dmitriev AA, Snezhkina AV and Kudryavtseva AV: Deregulation of glycolysis in cancer: Glyceraldehyde-3phosphate dehydrogenase as a therapeutic target. Expert Opin Ther Targets 17: 681-693, 2013.

32. Feng C, Gao Y, Wang C, Yu X, Zhang W, Guan H, Shan Z and Teng W: Aberrant overexpression of pyruvate kinase M2 is associated with aggressive tumor features and the BRAF mutation in papillary thyroid cancer. J Clin Endocrinol Metab 98: E1524-E1533, 2013.

33. Azoitei N, Becher A, Steinestel K, Rouhi A, Diepold K, Genze F, Simmet $\mathrm{T}$ and Seufferlein T: PKM2 promotes tumor angiogenesis by regulating HIF-1 $\alpha$ through NF- $x \mathrm{~B}$ activation. Mol Cancer 15 : 3, 2016.

34. Lu W, Cao Y, Zhang Y, Li S, Gao J, Wang XA, Mu J, Hu YP, Jiang L, Dong P, et al: Up-regulation of PKM2 promote malignancy and related to adverse prognostic risk factor in human gallbladder cancer. Sci Rep 6: 26351, 2016.

35. Wittwer JA, Robbins D, Wang F, Codarin S, Shen X, Kevil CG, Huang TT, Van Remmen H, Richardson A and Zhao Y: Enhancing mitochondrial respiration suppresses tumor promoter TPA-induced PKM2 expression and cell transformation in skin epidermal JB6 cells. Cancer Prev Res (Phila) 4: 1476-1484, 2011.

36. Le A, Cooper CR, Gouw AM, Dinavahi R, Maitra A, Deck LM, Royer RE, Vander Jagt DL, Semenza GL and Dang CV: Inhibition of lactate dehydrogenase A induces oxidative stress and inhibits tumor progression. Proc Natl Acad Sci USA 107: 2037-2042, 2010

37. Linnane AW, Marzuki S, Ozawa T and Tanaka M: Mitochondrial DNA mutations as an important contributor to ageing and degenerative diseases. Lancet 1: 642-645, 1989.

38. Taylor RW and Turnbull DM: Mitochondrial DNA mutations in human disease. Nat Rev Genet 6: 389-402, 2005.

39. Fliss MS, Usadel H, Caballero OL, Wu L, Buta MR, Eleff SM, Jen J and Sidransky D: Facile detection of mitochondrial DNA mutations in tumors and bodily fluids. Science 287: 2017-2019, 2000.

40. Cardaci S and Ciriolo MR: TCA cycle defects and cancer: When metabolism tunes redox state. Int J Cell Biol 2012: 161837, 2012.

41. Rustin P, Bourgeron T, Parfait B, Chretien D, Munnich A and Rötig A: Inborn errors of the Krebs cycle: A group of unusual mitochondrial diseases in human. Biochim Biophys Acta 1361: 185-197, 1997.

42. Singh KK, Desouki MM, Franklin RB and Costello LC: Mitochondrial aconitase and citrate metabolism in malignant and nonmalignant human prostate tissues. Mol Cancer 5: 14, 2006.

43. Parsons DW, Jones S, Zhang X, Lin JC, Leary RJ, Angenendt P, Mankoo P, Carter H, Siu IM, Gallia GL, et al: An integrated genomic analysis of human glioblastoma multiforme. Science 321: 1807-1812, 2008.

44. Yan H, Parsons DW, Jin G, McLendon R, Rasheed BA, Yuan W, Kos I, Batinic-Haberle I, Jones S, Riggins GJ, et al: IDH1 and IDH2 mutations in gliomas. N Engl J Med 360: 765-773, 2009.

45. Dang L, White DW, Gross S, Bennett BD, Bittinger MA, Driggers EM, Fantin VR, Jang HG, Jin S, Keenan MC, et al: Cancer-associated IDH1 mutations produce 2-hydroxyglutarate. Nature 462: 739-744, 2009.

46. Toro JR, Nickerson ML, Wei MH, Warren MB, Glenn GM, Turner ML, Stewart L, Duray P, Tourre O, Sharma N, et al: Mutations in the fumarate hydratase gene cause hereditary leiomyomatosis and renal cell cancer in families in North America. Am J Hum Genet 73: 95-106, 2003.

47. Chen YB, Brannon AR, Toubaji A, Dudas ME, Won HH, Al-Ahmadie HA, Fine SW, Gopalan A, Frizzell N, Voss MH, et al: Hereditary leiomyomatosis and renal cell carcinoma syndromeassociated renal cancer: Recognition of the syndrome by pathologic features and the utility of detecting aberrant succination by immunohistochemistry. Am J Surg Pathol 38: 627-637, 2014.

48. Frezza C, Zheng L, Folger O, Rajagopalan KN, MacKenzie ED, Jerby L, Micaroni M, Chaneton B, Adam J, Hedley A, et al: Haem oxygenase is synthetically lethal with the tumour suppressor fumarate hydratase. Nature 477: 225-228, 2011.

49. Gaude E and Frezza C: Defects in mitochondrial metabolism and cancer. Cancer Metab 2: 10, 2014.

50. Neumann HP, Pawlu C, Pęczkowska M, Bausch B, McWhinney SR, Muresan M, Buchta M, Franke G, Klisch J, Bley TA, et al: European-American Paraganglioma Study Group: Distinct clinical features of paraganglioma syndromes associated with SDHB and SDHD gene mutations. JAMA 292: 943-951, 2004. 
51. Pollard PJ, Wortham NC and Tomlinson IP: The TCA cycle and tumorigenesis: The examples of fumarate hydratase and succinate dehydrogenase. Ann Med 35: 632-639, 2003.

52. Pollard PJ, Brière JJ, Alam NA, Barwell J, Barclay E, Wortham NC, Hunt T, Mitchell M, Olpin S, Moat SJ, et al: Accumulation of Krebs cycle intermediates and over-expression of HIF1 $\alpha$ in tumours which result from germline FH and SDH mutations. Hum Mol Genet 14: 2231-2239, 2005.

53. Habano W, Sugai T, Nakamura S, Uesugi N, Higuchi T, Terashima $\mathrm{M}$ and Horiuchi S: Reduced expression and loss of heterozygosity of the SDHD gene in colorectal and gastric cancer. Oncol Rep 10: 1375-1380, 2003.

54. Selak MA, Armour SM, MacKenzie ED, Boulahbel H, Watson DG, Mansfield KD, Pan Y, Simon MC, Thompson CB and Gottlieb E: Succinate links TCA cycle dysfunction to oncogenesis by inhibiting HIF- $\alpha$ prolyl hydroxylase. Cancer Cell 7: 77-85, 2005.

55. Patra KC and Hay N: The pentose phosphate pathway and cancer. Trends Biochem Sci 39: 347-354, 2014.

56. Deberardinis RJ, Sayed N, Ditsworth D and Thompson CB Brick by brick: Metabolism and tumor cell growth. Curr Opin Genet Dev 18: 54-61, 2008.

57. Riganti C, Gazzano E, Polimeni M, Aldieri E and Ghigo D: The pentose phosphate pathway: An antioxidant defense and a crossroad in tumor cell fate. Free Radic Biol Med 53: 421-436, 2012

58. Jiang $\mathrm{P}, \mathrm{Du} \mathrm{W}$ and $\mathrm{Wu} \mathrm{M}$ : Regulation of the pentose phosphate pathway in cancer. Protein Cell 5: 592-602, 2014.

59. Cairns RA, Harris IS and Mak TW: Regulation of cancer cell metabolism. Nat Rev Cancer 11: 85-95, 2011.

60. Jonas SK, Benedetto C, Flatman A, Hammond RH, Micheletti L, Riley C, Riley PA, Spargo DJ, Zonca M and Slater TF: Increased activity of 6-phosphogluconate dehydrogenase and glucose-6phosphate dehydrogenase in purified cell suspensions and single cells from the uterine cervix in cervical intraepithelial neoplasia. Br J Cancer 66: 185-191, 1992.

61. Lucarelli G, Galleggiante V, Rutigliano M, Sanguedolce F, Cagiano S, Bufo P, Lastilla G, Maiorano E, Ribatti D, Giglio A, et al: Metabolomic profile of glycolysis and the pentose phosphate pathway identifies the central role of glucose6-phosphate dehydrogenase in clear cell-renal cell carcinoma. Oncotarget 6: 13371-13386, 2015.

62. D'Alessandro A, Amelio I, Berkers CR, Antonov A, Vousden KH Melino G and Zolla L: Metabolic effect of TAp63 $\alpha$ : Enhanced glycolysis and pentose phosphate pathway, resulting in increased antioxidant defense. Oncotarget 5: 7722-7733, 2014.

63. Sukhatme VP and Chan B: Glycolytic cancer cells lacking 6-phosphogluconate dehydrogenase metabolize glucose to induce senescence. FEBS Lett 586: 2389-2395, 2012.

64. Nishimura M and Uyeda K: Purification and characterization of a novel xylulose 5-phosphate-activated protein phosphatasecatalyzing dephosphorylation of fructose-6-phosphate,2-kinase:fructose2,6-bisphosphatase. J Biol Chem 270: 26341-26346, 1995.

65. Wise DR and Thompson CB: Glutamine addiction: A new therapeutic target in cancer. Trends Biochem Sci 35: 427-433, 2010

66. DeBerardinis RJ and Cheng T: Q's next: The diverse functions of glutamine in metabolism, cell biology and cancer. Oncogene 29 313-324, 2010.

67. Dang CV: Glutaminolysis: Supplying carbon or nitrogen or both for cancer cells? Cell Cycle 9: 3884-3886, 2010.

68. Altman BJ, Stine ZE and Dang CV: From Krebs to clinic: Glutamine metabolism to cancer therapy. Nat Rev Cancer 16: 619-634, 2016

69. Hensley CT, Wasti AT and DeBerardinis RJ: Glutamine and cancer: Cell biology, physiology, and clinical opportunities. J Clin Invest 123: 3678-3684, 2013.

70. Wise DR, DeBerardinis RJ, Mancuso A, Sayed N, Zhang XY, Pfeiffer HK, Nissim I, Daikhin E, Yudkoff M, McMahon SB, et al: Myc regulates a transcriptional program that stimulates mitochondrial glutaminolysis and leads to glutamine addiction. Proc Natl Acad Sci USA 105: 18782-18787, 2008.

71. Stepulak A, Luksch H, Gebhardt C, Uckermann O, Marzahn J, Sifringer M, Rzeski W, Staufner C, Brocke KS, Turski L, et al: Expression of glutamate receptor subunits in human cancers. Histochem Cell Biol 132: 435-445, 2009.

72. Durán RV, Oppliger W, Robitaille AM, Heiserich L, Skendaj R, Gottlieb E and Hall MN: Glutaminolysis activates Rag-mTORC1 signaling. Mol Cell 47: 349-358, 2012.

73. Jain M, Nilsson R, Sharma S, Madhusudhan N, Kitami T, Souza AL, Kafri R, Kirschner MW, Clish CB and Mootha VK: Metabolite profiling identifies a key role for glycine in rapid cancer cell proliferation. Science 336: 1040-1044, 2012.
74. Amelio I, Cutruzzolá F, Antonov A, Agostini M and Melino G: Serine and glycine metabolism in cancer. Trends Biochem Sci 39: 191-198, 2014.

75. Hasegawa S, Ichiyama T, Sonaka I, Ohsaki A, Okada S, Wakiguchi H, Kudo K, Kittaka S, Hara M and Furukawa S: Cysteine, histidine and glycine exhibit anti-inflammatory effects in human coronary arterial endothelial cells. Clin Exp Immunol 167: 269-274, 2012

76. Alarcon-Aguilar FJ, Almanza-Perez J, Blancas G, Angeles S, Garcia-Macedo R, Roman R and Cruz M: Glycine regulates the production of pro-inflammatory cytokines in lean and monosodium glutamate-obese mice. Eur J Pharmacol 599: 152-158, 2008.

77. Cruz M, Maldonado-Bernal C, Mondragón-Gonzalez R, Sanchez-Barrera R, Wacher NH, Carvajal-Sandoval G and Kumate J: Glycine treatment decreases proinflammatory cytokines and increases interferon- $\gamma$ in patients with type 2 diabetes. J Endocrinol Invest 31: 694-699, 2008.

78. Zhang WC, Shyh-Chang N, Yang H, Rai A, Umashankar S, Ma S, Soh BS, Sun LL, Tai BC, Nga ME, et al: Glycine decarboxylase activity drives non-small cell lung cancer tumor-initiating cells and tumorigenesis. Cell 148: 259-272, 2012.

79. Locasale JW: Serine, glycine and one-carbon units: Cancer metabolism in full circle. Nat Rev Cancer 13: 572-583, 2013.

80. Possemato R, Marks KM, Shaul YD, Pacold ME, Kim D, Birsoy K, Sethumadhavan S, Woo HK, Jang HG, Jha AK, et al: Functional genomics reveal that the serine synthesis pathway is essential in breast cancer. Nature 476: 346-350, 2011.

81. Locasale JW, Grassian AR, Melman T, Lyssiotis CA, Mattaini KR, Bass AJ, Heffron G, Metallo CM, Muranen T, Sharfi H, et al: Phosphoglycerate dehydrogenase diverts glycolytic flux and contributes to oncogenesis. Nat Genet 43: 869-874, 2011

82. Mattaini KR, Sullivan MR and Vander Heiden MG: The importance of serine metabolism in cancer. J Cell Biol 214: 249-257, 2016.

83. Baenke F, Peck B, Miess H and Schulze A: Hooked on fat: The role of lipid synthesis in cancer metabolism and tumour development. Dis Model Mech 6: 1353-1363, 2013.

84. Santos CR and Schulze A: Lipid metabolism in cancer. FEBS J 279: 2610-2623, 2012.

85. Currie E, Schulze A, Zechner R, Walther TC and Farese RV Jr: Cellular fatty acid metabolism and cancer. Cell Metab 18: 153-161, 2013.

86. Vance JE and Vance DE: Biochemistry of lipids, lipoproteins and membranes. Elsevier, Amsterdam, 2002.

87. Bauer DE, Hatzivassiliou G, Zhao F, Andreadis C and Thompson CB: ATP citrate lyase is an important component of cell growth and transformation. Oncogene 24: 6314-6322, 2005.

88. Qian X, Hu J, Zhao J and Chen H: ATP citrate lyase expression is associated with advanced stage and prognosis in gastric adenocarcinoma. Int J Clin Exp Med 8: 7855-7860, 2015.

89. Xin M, Qiao Z, Li J, Liu J, Song S, Zhao X, Miao P, Tang T, Wang L, Liu W, et al: miR-22 inhibits tumor growth and metastasis by targeting ATP citrate lyase: Evidence in osteosarcoma, prostate cancer, cervical cancer and lung cancer. Oncotarget 7: 44252-44265, 2016.

90. Lucenay KS, Doostan I, Karakas C, Bui T, Ding Z, Mills GB, Hunt KK and Keyomarsi K: Cyclin E associates with the lipogenic enzyme ATP-citrate lyase to enable malignant growth of breast cancer cells. Cancer Res 76: 2406-2418, 2016

91. Su YW, Lin YH, Pai MH, Lo AC, Lee YC, Fang IC, Lin J, Hsieh RK, Chang YF and Chen CL: Association between phosphorylated AMP-activated protein kinase and acetyl-CoA carboxylase expression and outcome in patients with squamous cell carcinoma of the head and neck. PLoS One 9: e96183, 2014

92. Wang MD, Wu H, Fu GB, Zhang HL, Zhou X, Tang L, Dong LW, Qin CJ, Huang S, Zhao LH, et al: Acetyl-coenzyme A carboxylase alpha promotion of glucose-mediated fatty acid synthesis enhances survival of hepatocellular carcinoma in mice and patients. Hepatology 63: 1272-1286, 2016

93. Bauerschlag DO, Maass N, Leonhardt P, Verburg FA, Pecks U, Zeppernick F, Morgenroth A, Mottaghy FM, Tolba R, Meinhold-Heerlein I, et al: Fatty acid synthase overexpression: Target for therapy and reversal of chemoresistance in ovarian cancer. J Transl Med 13: 146, 2015

94. Ogino S, Kawasaki T, Ogawa A, Kirkner GJ, Loda M and Fuchs CS: Fatty acid synthase overexpression in colorectal cancer is associated with microsatellite instability, independent of $\mathrm{CpG}$ island methylator phenotype. Hum Pathol 38: 842-849, 2007. 
95. Gong J, Shen S, Yang Y, Qin S, Huang L, Zhang H, Chen L, Chen Y,Li S, She S, et al: Inhibition of FASN suppresses migration, invasion and growth in hepatoma carcinoma cells by deregulating the HIF-1 $\alpha /$ IGFBP1 pathway. Int J Oncol 50: 883-892, 2017.

96. Carracedo A, Cantley LC and Pandolfi PP: Cancer metabolism: Fatty acid oxidation in the limelight. Nat Rev Cancer 13: 227-232, 2013.

97. Ito K and Suda T: Metabolic requirements for the maintenance of self-renewing stem cells. Nat Rev Mol Cell Biol 15: 243-256, 2014.

98.Zaugg K, Yao Y, Reilly PT, Kannan K, Kiarash R, Mason J, Huang P, Sawyer SK, Fuerth B, Faubert B, et al: Carnitine palmitoyltransferase $1 \mathrm{C}$ promotes cell survival and tumor growth under conditions of metabolic stress. Genes Dev 25: 1041-1051, 2011.

99. McGarry JD and Brown NF: The mitochondrial carnitine palmitoyltransferase system. From concept to molecular analysis. Eur J Biochem 244: 1-14, 1997.

100. Coller HA: Is cancer a metabolic disease? Am J Pathol 184: 4-17, 2014.

101. Tan DJ, Bai RK and Wong LJ: Comprehensive scanning of somatic mitochondrial DNA mutations in breast cancer. Cancer Res 62: 972-976, 2002.

102.Liu VW, Shi HH, Cheung AN, Chiu PM, Leung TW, Nagley P, Wong LC and Ngan HY: High incidence of somatic mitochondrial DNA mutations in human ovarian carcinomas. Cancer Res 61: 5998-6001, 2001.

103. Richard SM, Bailliet G, Páez GL, Bianchi MS, Peltomäki P and Bianchi NO: Nuclear and mitochondrial genome instability in human breast cancer. Cancer Res 60: 4231-4237, 2000.

104.Ishikawa K, Takenaga K, Akimoto M, Koshikawa N, Yamaguchi A, Imanishi H, Nakada K, Honma Y and Hayashi J: ROS-generating mitochondrial DNA mutations can regulate tumor cell metastasis. Science 320: 661-664, 2008.
105. Swalwell H, Kirby DM, Blakely EL, Mitchell A, Salemi R, Sugiana C, Compton AG, Tucker EJ, Ke BX, Lamont PJ, et al: Respiratory chain complex I deficiency caused by mitochondrial DNA mutations. Eur J Hum Genet 19: 769-775, 2011.

106. Kwong JQ, Henning MS, Starkov AA and Manfredi G: The mitochondrial respiratory chain is a modulator of apoptosis. J Cell Biol 179: 1163-1177, 2007.

107. Osellame LD, Blacker TS and Duchen MR: Cellular and molecular mechanisms of mitochondrial function. Best Pract Res Clin Endocrinol Metab 26: 711-723, 2012.

108. Shen YH, Wang XL and Wilcken DE: Nitric oxide induces and inhibits apoptosis through different pathways. FEBS Lett 433: 125-131, 1998.

109. Seiler N and Raul F: Polyamines and apoptosis. J Cell Mol Med 9: 623-642, 2005.

110. Agostinelli E, Tempera G, Molinari A, Salvi M, Battaglia V, Toninello A and Arancia G: The physiological role of biogenic amines redox reactions in mitochondria. New perspectives in cancer therapy. Amino Acids 33: 175-187, 2007.

111. Grancara S, Ohkubo S, Artico M, Ciccariello M, Manente S, Bragadin M, Toninello A and Agostinelli E: Milestones and recent discoveries on cell death mediated by mitochondria and their interactions with biologically active amines. Amino Acids 48: 2313-2326, 2016.

This work is licensed under a Creative Commons Attribution-NonCommercial-NoDerivatives 4.0 International (CC BY-NC-ND 4.0) License. 